\title{
Possibilidades didáticas do uso de um filme para discutir a Natureza da Ciência (NdC)
}

\author{
Didactic possibilities of using a film to discuss the Nature of Science \\ (NOS)

\section{Posibilidades didácticas de utilizar una película para discutir la naturaleza de la ciencia (NdC)}

\author{
Laís Mendes Alvarenga (lais.mendes@ sou.unifal-mg.edu.br) \\ Universidade Federal de Alfenas (UNIFAL-MG).
}

Elaine Angelina Colagrande (elaine.colagrande@unifal-mg.edu.br)

Universidade Federal de Alfenas (UNIFAL-MG).

Resumo: O objetivo deste trabalho foi investigar as possibilidades didáticas da utilização do filme "Estrelas Além do Tempo" como recurso didático para discutir aspectos consensuais da Natureza da Ciência $(\mathrm{NdC})$ em diferentes níveis de ensino. Ainda que a finalidade do filme não seja exatamente pedagógica, ele pode auxiliar na formação cultural e social, favorecendo reflexões sobre a Ciência. Tal ideia surgiu a partir da leitura de pesquisas cujos resultados evidenciam concepções reducionistas ou equivocadas acerca do cientista e do desenvolvimento da Ciência, tanto de estudantes quanto de professores. Para identificar as possibilidades, o filme foi assistido na íntegra por várias vezes, culminando com a seleção de um conjunto de cenas consideradas relevantes para discutir aspectos da NdC. Posteriormente foi realizada a análise fílmica de conteúdo, buscando, nas cenas selecionadas, pontos de diálogo com quatro aspectos consensuais da $\mathrm{NdC}$ presentes na literatura e identificados no filme. Os resultados da análise fílmica apontaram a existência de cenas que permitem visualizar a relação entre o contexto histórico, filosófico e cultural no desenvolvimento do conhecimento científico e são, portanto, ferramentas potenciais para promover discussões sobre a $\mathrm{NdC}$ em sala de aula.

Palavras-chave: Natureza da Ciência; Ensino de Ciências; Filmes no Ensino.

Abstract: The objective of this work was to investigate didactic possibilities regarding the motion picture Hidden Figures as a didactic resource to discuss consensual aspects of the Nature of Science (NOS) at different levels of teaching. Although the purpose of the film is not exactly pedagogical, it can help in cultural and social development, favoring reflections on Science. This idea arose from the reading of research explaining reductionist or mistaken conceptions about the scientists and the development of science, concerning both students and teachers. To identify the possibilities, the movie was watched in full length, several times, culminating in the selection of a set of scenes considered relevant to discuss aspects of NOS. Later, the film analysis of content was conducted in the selected scenes, seeking dialogue points with four consensual aspects of NOS present in the literature and identified in the film. The results of the film

Recebido em: 17/05/2021

Aceite em: $31 / 08 / 2021$ 
analysis pointed out the existence of scenes that allow visualizing the relationship between the historical, philosophical, and cultural context in the development of scientific knowledge and they are, therefore, potential tools to promote discussions about NOS in the classroom.

Keywords: Nature of Science; Science teaching; Films in teaching

Resumen: El objetivo de este trabajo fue investigar las posibilidades didácticas en el uso de la película Hidden Figures como una función didáctica para la discusión de los aspectos consensuados de la Naturaleza de la Ciencia (NdC) en distintos niveles de enseñanza. Aunque el propósito de la película no sea precisamente para el uso pedagógico, es posible que ayude en una formación cultural y social, favoreciendo las reflexiones acerca de la Ciencia. Esta idea surgió después de la lectura de investigaciones cuyos resultados sugieren concepciones o reduccionistas o erróneas, tanto de estudiantes como de profesores, sobre el científico y también sobre el desarrollo. Para identificar las posibilidades, la película fue vista en su totalidad varias veces, y culminó en la selección de un conjunto de escenas que fueran consideradas relevantes para la discusión de los aspectos de la NdC. Posteriormente se realizó el análisis fílmico del contenido en que se busca en las escenas seleccionadas puntos de diálogo en cuatro aspectos consensuados de $\mathrm{NdC}$ que son presentes en la literatura y identificados en la película. Los resultados del análisis cinematográfico señalaron la existencia de escenas que permiten visualizar la relación entre el contexto histórico, filosófico y cultural en el desarrollo del conocimiento científico y son, por lo tanto, herramientas potenciales para lograr discusiones sobre la $\mathrm{NdC}$ en las clases.

Palabras-clave: Naturaleza de la Ciencia; Enseñanza de las ciencias; Películas en educación.

\section{INTRODUÇÃO}

Diversas pesquisas na área do ensino de Ciências destacam a necessidade de as aulas de Ciências da Natureza integrarem aspectos sobre como o conhecimento científico se desenvolve, ou seja, como são os processos para sua construção e como se dão as influências do contexto histórico e cultural sobre isso, atentando para a importância de que essas aulas promovam debates sobre o que chamamos a Natureza da Ciência (NdC) (MOURA, 2014; MATTHEWS, 1995; LEDERMAN, 2006; BORRÁS, 2010). Pesquisas nacionais e internacionais evidenciam um cenário no qual professores(as) e estudantes de ensino médio, fundamental e da modalidade EJA, de variados cursos, possuem concepções inadequadas, distorcidas ou reducionistas acerca da Ciência, do cientista e da NdC (POMBO; LAMBACH, 2016; MESQUITA, SOARES, 2008; SILVA; SANTANA; ARROIO, 2012; KOSMINSKY; GIORDAN, 2002). A NdC conta com contribuições da Filosofia, da Sociologia e da História da

Recebido em: 17/05/2021

Aceite em: $31 / 08 / 2021$ 
Ciência, áreas de conhecimento que trazem contextos essenciais para uma compreensão crítica sobre o que realmente é Ciência, compreensão tal que pode (re)significar as concepções reveladas por estudantes e docentes.

Segundo Colagrande e Arroio (2018), a Filosofia da Ciência traz os aspectos que embasam discussões acerca da gênese do conhecimento científico, além de fatores internos e externos que o influenciam. A Sociologia da Ciência evidencia a relação entre o contexto social e a Ciência, e a História da Ciência revela os diferentes contextos e momentos históricos em que as produções científicas aconteceram. O conceito de NdC, portanto, engloba uma variedade de aspectos sobre o funcionamento das Ciências, como se constrói e se desenvolve o conhecimento científico produzido, quais os métodos necessários para validar esse conhecimento, a natureza da comunidade científica, os vínculos com a tecnologia, as relações da sociedade com o sistema tecnocientífico e vice-versa, além das influências desse desenvolvimento sobre a cultura e o progresso da sociedade (VÁZQUEZ; MANASSERO; ACEVEDO; ACEVEDO, 2008; DE ARAÚJO SILVA; ROBAINA, 2020).

Os aspectos filosóficos, sociais e históricos contribuem, assim, para o entendimento dos conceitos da $\mathrm{NdC}$ e podem favorecer a aprendizagem dos conteúdos de Ciências da Natureza, pois, em geral, as aulas das disciplinas de Ciências Naturais são descontextualizadas e fragmentadas, podendo gerar dificuldades nos(as) estudantes no que diz respeito à compreensão do processo de construção da Ciência, abrindo espaço para concepções distorcidas a seu respeito (ROSA, 2000). Evidentemente a NdC não trará a resolução de todas as limitações que o ensino de Ciências enfrenta atualmente, no entanto traz possibilidades, como Matthews (1995, p.165) evidência:

\footnotetext{
A história, a filosofia e a sociologia da ciência podem humanizar as ciências e aproximá-las dos interesses pessoais, éticos, culturais e políticos da comunidade; podem tornar as aulas de ciências mais desafiadoras e reflexivas, permitindo, deste modo, o desenvolvimento do pensamento crítico; podem contribuir para um entendimento mais integral de matéria científica [...] podem melhorar a formação do professor auxiliando o desenvolvimento de uma epistemologia da ciência mais rica e mais autêntica, ou seja, de uma maior compreensão da estrutura das ciências bem como do espaço que ocupam no sistema intelectual das coisas.
}

Segundo Meglhioratti, Bortolozzi e Caldeira (2005), ao considerarmos o mundo de tecnologia e informação em que vivemos hoje, a apropriação do conhecimento desenvolvido pela humanidade ao longo da história é uma forma de poder que prepara o 
indivíduo para ação social transformadora e crítica. Isso porque a compreensão da produção do conhecimento científico como uma ação dinâmica, subjetiva e ligada a fatores socioculturais é essencial para exercer a cidadania de forma crítica e auxiliar na alfabetização científica, que se constitui como a capacidade de analisar, avaliar e de tomar decisões em situações relacionadas à Ciência e seu desenvolvimento (SASSERON, 2015; FANFA et al., 2020). Portanto, compreender a NdC possibilita que os conteúdos científicos façam sentido, auxiliando o aprendizado e gerando a valorização desses conhecimentos como parte da cultura contemporânea, além de favorecer a compreensão dos compromissos que a comunidade científica tem com a sociedade (LEDERMAN, 2006).

Todas essas possibilidades se tornam importantes em um cenário no qual professores e alunos de Ciências apresentam uma visão inadequada ou equivocada acerca do conhecimento científico e de como ocorre seu desenvolvimento (MEGLHIORATTI; BORTOLOZZI; CALDEIRA, 2005). A análise da construção científica pode auxiliar na compreensão dos alunos sobre a constituição de uma comunidade científica, a relação entre ciência e sociedade e também sobre as barreiras epistemológicas superadas pelos cientistas (MEGLHIORATTI; BORTOLOZZI; CALDEIRA, 2005; DE ARAÚJO SILVA; ROBAINA, 2020).

\subsection{RELEVÂNCIA DA NATUREZA DA CIÊNCIA PARA O ENSINO DE CIENCIAS}

A Base Nacional Comum Curricular (BNCC), ao evidenciar as aprendizagens essenciais que todos(as) os(as) alunos(as) devem desenvolver ao longo das etapas e modalidades da educação básica, deixa claro que na área das Ciências da Natureza:

[...] são imprescindíveis tanto conhecimentos éticos, políticos e culturais quanto científicos. Isso por si só já justifica, o compromisso da área de Ciências da Natureza com a formação integral dos alunos [..] e para o desenvolvimento do letramento científico, que envolve a capacidade de compreender e interpretar o mundo (natural, social e tecnológico), mas também de transformá-lo com base nos aportes teóricos e processuais das ciências. Em outras palavras, apreender ciência não é a finalidade última do letramento, mas, sim, o desenvolvimento da capacidade de atuação no e sobre o mundo, importante ao exercício pleno da cidadania. Nessa perspectiva, a área de Ciências da Natureza, por meio de um olhar articulado de diversos campos do saber, precisa assegurar aos alunos do Ensino Fundamental o acesso à diversidade de conhecimentos científicos produzidos ao longo da história, bem como a aproximação gradativa aos principais processos, práticas e procedimentos da investigação científica. Espera-se, desse modo, possibilitar que esses alunos tenham um novo olhar sobre o mundo que os

Recebido em: 17/05/2021

Aceite em: $31 / 08 / 2021$ 
Com relação às competências específicas referentes ao ensino das Ciências da Natureza, a BNCC mostra que uma delas é: "compreender as Ciências da Natureza como empreendimento humano, e o conhecimento científico como provisório, cultural e histórico" (BRASIL, 2018, p.324). Os Parâmetros Curriculares Nacionais do Ensino Médio (PCNEM) propõem aspectos da Sociologia da Ciência em seus objetivos para a área de Ciências da Natureza, pois eles "incluem compreender as Ciências da Natureza como construções humanas e a relação entre conhecimento científico-tecnológico e a vida social e produtiva; objetivos usualmente restritos ao aprendizado das Ciências Humanas" (BRASIL,1999, p.11), além disso:

[...] o exercício histórico daria aos estudantes uma oportunidade de questionar e compreender melhor processos sociais, econômicos e culturais passados e contemporâneos e, além disso, auxiliaria a construir uma visão das Ciências da Natureza associada a outras dimensões da vida humana [...]apresentar as ciências e técnicas como construções históricas, com participação permanente no desenvolvimento social, econômico e cultural (BRASIL, 1999, p.18 e 23).

No que diz respeito às competências destinadas para o Ensino Médio, os documentos oficiais citados destacam a necessidade de "contextualização das ciências no âmbito sócio-cultural, na forma de análise crítica das ideias e dos recursos da área e das questões do mundo que podem ser respondidas ou transformadas por meio do pensar e do conhecimento científico" (BRASIL,1999, p.112). Torna-se evidente que aspectos da Natureza da Ciência constituem hoje um dos elementos centrais da alfabetização científica e tecnológica para todas as pessoas e, portanto, configuram-se como competências essenciais do currículo de Ciências, que inspira a educação científica do presente e também a formação de cidadãos (ACEVEDO; VÁZQUEZ; MANASSERO, 2002).

Pesquisas vêm discutindo as concepções inadequadas, reducionistas ou estereotipadas que estudantes possuem sobre o trabalho científico, sobre a Ciência e sua natureza (POMBO; LAMBACH, 2016; MESQUITA, SOARES, 2008; PORLÁN, 1989). Tais concepções podem causar dificuldades na compreensão dos conteúdos de Ciências e de como ocorre a construção dos conhecimentos científicos. Santana e Arroio (2012) e Kosminsky e Giordan (2002), ao analisarem os desenhos de discentes 
de ensino fundamental, apresentaram resultados que evidenciam a importância da $\mathrm{NdC}$. Esses resultados da pesquisa sugerem que a maioria dos discentes possuem uma ideia estereotipada e distorcida do cientista e do trabalho científico.

Harres (1999) realizou uma revisão de pesquisas sobre concepções de professores a respeito da $\mathrm{NdC}$ e mostrou em sua análise que as concepções mais comuns são: a visão de que a ciência busca a verdade incontestável através de uma metodologia indutiva e sem influências externas, e a concepção absolutista de ciência, baseada numa metodologia científica imutável e na crença em uma superioridade do conhecimento científico. Assim, ideias equivocadas sobre ciência podem ser transmitidas pelos professores durantes as aulas, influenciando o desenvolvimento científico dos estudantes. Por isso, a compreensão dos aspectos da $\mathrm{NdC}$ pelos professores pode ser uma ferramenta potencial para mudar esse cenário.

Nesse sentido, Harres (1999), ao analisar a pesquisa de Lederman (1992), observa que os resultados foram favoráveis quanto às concepções sobre $\mathrm{NdC}$ de professores que participaram de cursos ou disciplinas de graduação direcionados a debates que englobaram conhecimentos sobre Filosofia, Sociologia e História da Ciência, que constituem a $\mathrm{NdC}$ (HARRES,1999). Já resultados de algumas pesquisas nacionais, como as de Lambach e Pombo (2016) e Mesquita e Soares (2008), sugerem uma defasagem que professores brasileiros participantes dessas pesquisas possuem na compreensão das Ciências e do seu desenvolvimento (LAMBACH; POMBO, 2016; MESQUITA, SOARES; 2008).

Mesquita e Soares (2008), após analisarem as visões inadequadas dos docentes, concluíram como a experimentação ainda é muito valorizada por eles(as), secundarizando outros aspectos que também são importantes, como a formulação de hipóteses e teorias, a etapa de investigação e a necessidade de argumentação. Essa valorização excessiva da experimentação durante as aulas pode representar para os(as) discentes uma ideia reducionista do conhecimento científico, deixando na imaginação dos(as) alunos(as), por exemplo, que na ciência a única forma de se produzir conhecimento é por meio da realização de experimentos ou medições para chegar em um resultado previsto. Por isso, é necessário discutir os diferentes processos e metodologias pelas quais a construção da Ciência percorre.

As visões inadequadas dos(as) professores(as) ocorrem, segundo Lederman (2006), pela falta de uma formação adequada que promova suporte às questões 
epistemológicas da Ciência e também que favoreça o desenvolvimento da criticidade do(a) docente para saber avaliar a sua realidade. Contudo, é importante deixar claro que apenas conhecer a $\mathrm{NdC}$ não é suficiente para que o(a) professor(a) melhorare as concepções de alunos(as) sobre Ciências (LEDERMAN, 2006). O(a) professor(a) necessita saber como incluir esse conhecimento sobre a $\mathrm{NdC}$ em suas aulas, sendo necessário abrir espaços para que esse aprendizado ocorra durante sua formação inicial ou continuada, bem como em eventos científicos, minicursos ou momentos educativos não formais.

Outro fator que possui influência sobre ambos os grupos (estudantes e professores) é a mídia televisiva, que pode muitas vezes mostrar uma imagem distorcida e estereotipada do cientista, de sua vida e do processo de construção dos conhecimentos científicos. Esse veículo influencia diretamente na formação de ideias. Os Parâmetros Curriculares Nacionais (1998) do terceiro e quarto ciclo do Ensino Fundamental trazem contribuições nesse sentido:

[...] é comum que crianças, jovens e adultos tenham acesso, pela televisão, a informações diversas que muitas vezes são fragmentadas, descontextualizadas, imprecisas, tendenciosas e até discriminatórias. Os alunos, embora ainda não tenham condições de compreendê-las plenamente, atribuem significado ao que veem. (BRASIL, 1998, p.143).

Reis, Rodrigues e Santos (2006) chamam atenção para o fato de crianças basearem sua visão de ciência em desenhos, filmes e jornais. Esse fator se torna ainda mais preocupante, segundo os autores, ao se considerar outros dois aspectos: 1) se essa imagem de ciência e cientista transmitida pela mídia for sensacionalista e estereotipada e 2) se a escola não discutir sobre a natureza da ciência de forma crítica em sala de aula. Portanto, é importante que as crianças e jovens desenvolvam criticidade frente as informações que têm acesso por esses e diversos outros meios de comunicação.

Atualmente é notória a urgência de que pessoas jovens e também adultas saibam interpretar com criticidade as informações às quais têm acesso. Isso se deve ao fato de que lidamos com o avanço de uma onda negacionista com relação à Ciência que coloca em risco a saúde e a segurança da população brasileira durante a pandemia de Covid-19, na qual:

[...] testemunhamos avanços de movimentos pseudocientíficos, anticientíficos e negacionistas da ciência. São movimentos que defendem premissas individualistas, crenças pessoais e opinativas, que distorcem fatos e evidências, e que tomaram força com a popularização tecnológica e das mídias sociais. As pessoas passaram a ser bombardeadas diariamente por

Recebido em: $17 / 05 / 2021$

Aceite em: $31 / 08 / 2021$ 
mentiras e notícias falsas (fake news e fake science), fenômeno denominado recentemente pela Organização Mundial da Saúde (OMS) de infodemia (infodemic) -boatos repletos de desinformação e anticiência acerca da Covid19 (OMS, 2020). A divulgação de notícias falsas sempre existiu. No entanto, o que observamos recentemente é sua utilização para fundamentar debates políticos, científicos, sociais [ARTHURY; GARCIA, 2020] e, de forma ainda mais preocupante, para propor e planejar políticas públicas (BARTELMEBS; VENTURI; DE SOUSA 2021, p.1-2).

Ações educacionais que possibilitem discussões sobre aspectos da $\mathrm{NdC}$ podem ser uma das formas capazes de auxiliar nesse cenário, no sentido de promover uma compreensão mais próxima da realidade de como o conhecimento científico se desenvolve e o motivo pelo qual não pode ser comparado à opiniões e crenças pessoais.

\subsection{ALGUNS ASPECTOS CONSENSUAIS ACERCA DA NDC}

A História, Filosofia e Sociologia da Ciência contam com uma gama de conhecimentos sobre a Ciência. Sendo assim, a tarefa de selecionar as informações necessárias a serem incorporadas nas aulas de Ciências Naturais não é trivial. Entretanto, diferentes autores trazem contribuições mais detalhadas dos aspectos que consideram importantes para compreender a $\mathrm{NdC}$, o que varia de acordo com o referencial e crenças de cada um deles, como acontece com a própria construção da Ciência. Mesmo que houvesse um consenso bem definido, cada professor(a) aderiria àquilo que considerasse mais coerente e mais importante para uma alfabetização científica que possibilite participação consciente dos sujeitos em decisões relativas à aplicação de novos conhecimentos científicos.

Azevedo e Scarpa (2017) encontraram, durante uma revisão sistemática dos artigos publicados até 2015 sobre os aspectos da NdC, 25 aspectos considerados consensuais. Entretanto, alguns desses aspectos da $\mathrm{NdC}$ aparecem com maior frequência nos artigos que outros. Estão descritos a seguir, assim, os consensos que se mostraram mais frequentes na literatura e que entendeu-se serem mais relevantes para compreender questões principais do desenvolvimento do conhecimento científico, auxiliar no desenvolvimento de cidadãos conscientes e promover melhor compreensão da análise do filme escolhido. Esses consensos incluem (LEDERMAN et al., 2007; MOURA, 2014; AZEVEDO, SCARP, 2012; PERÉZ et al., 2001; PRAIA et al, 2007): 1) A Ciência é influenciada pelo contexto social, cultural, político etc., no qual ela é 
construída; 2) A Ciência é mutável, dinâmica e tem como objetivo buscar explicar os fenômenos naturais; 3) Ciência, tecnologia e sociedade são correlacionadas; 4) Não existe um único método científico; 5) A teoria não é consequência da observação/experimento e vice-versa.

\subsection{FILMES COMO RECURSO DIDÁTICO NO ENSINO DE CIÊNCIAS}

O uso de audiovisuais como recurso didático pode favorecer o ensino e a aprendizagem, pois tais adventos possuem influência direta em vários aspectos de nossas vidas, e geralmente estão muito presentes no cotidiano da sociedade em que vivemos (ROSA, 2000). A nova geração que ocupa as escolas, institutos e universidades possui familiarização com o audiovisual, o que acaba por favorecer esse público, pois ele desenvolveu um pensamento visual como parte intrínseca de seu desenvolvimento cognitivo e como forma de comunicação (ELBA; JESÚS; MANUEL, 2004). Ainda que a função dos filmes de entretenimento, como o escolhido para esta proposta, não seja exatamente educativa, eles funcionam como forma de educar culturalmente, socialmente ou cientificamente, pois podem influenciar as atitudes, o comportamento e até o desenvolvimento dos espectadores, sendo, portanto, uma fonte de inspiração que pode interferir e auxiliar na construção de representações e de percepções sobre determinados temas ou assuntos (DOS SANTOS; DE ARAÚJO, 2020).

O cinema (entre outras mídias) se tornou uma nova fonte de informações para os(as) estudantes e, assim, surge a necessidade de ações pedagógicas associadas a essa mídia, com a intenção de auxiliar os cidadãos no desenvolvimento de competências para a compreensão de informações e mensagens. Aquino e Santos (2011) evidenciam que o cinema é parte de nossa cultura e, se utilizado em sala de aula com organização e mediação do(a) professor(a), pode auxiliar na construção de uma postura crítica, reflexiva e analítica no(a) aluno(a), seja com relação às próprias obras ou à realidade em que está inserido (DE ARAÚJO SILVA; ROBAINA, 2020; NAPOLITANO, 2006). Carrera e Arroio (2012) também trazem as possibilidades de se desenvolver atividades pedagógicas com filmes:

A vantagem oferecida pelos filmes é que eles podem transcender variáveis de tempo e espaço levando o espectador a vários ambientes sem a necessidade de locomoção [...] é possível trazer exemplificações visuais de situações que os alunos não teriam oportunidade de presenciar nas aulas, o que torna o

Recebido em: $17 / 05 / 2021$

Aceite em: $31 / 08 / 2021$ 
Para que um filme possa ser utilizado como recurso didático é interessante que ele se enquadre dentro dos objetivos do(a) professor(a), à faixa etária dos(as) alunos(as) e que possua informações que estejam de acordo com os conceitos científicos a serem trabalhados. Portanto, é importante salientar que, ao desenvolver atividades com filmes, o(a) docente deve propor leituras cautelosas e críticas, julgando a veracidade das informações que o compõem, realizando assim uma ponte entre emoção e razão de maneira direcionada aos objetivos pedagógicos do uso do filme, incentivando os(as) estudantes a se tornarem espectadores mais ativos, exigentes e críticos, propondo relações do conteúdo do filme com o conteúdo escolar (NAPOLITANO, 2006). Por isso, no âmbito escolar, um filme utilizado como recurso com o intuito de ensinar sobre Ciência, deve levar em conta quais aspectos serão observados, bem como a sua coerência, uma vez que o meio cinematográfico produz um conhecimento sobre Ciência de uma forma não científica, pois não é dirigido por um especialista, podendo gerar uma visão incorreta do conhecimento científico (BORRÁS, 2010).

A partir do quadro apresentado, no qual discutiu-se a importância da NdC nas aulas de Ciências Naturais e também o potencial didático do uso de filmes, surgiu a intenção de realizar esta pesquisa, cujo objetivo foi identificar no filme "Estrelas além do tempo" cenas com potencialidades para mediar discussões acerca de alguns aspectos da $\mathrm{NdC}$ em sala de aula.

\section{METODOLOGIA}

O filme "Estrelas além do Tempo" (Hidden Figures), produzido em 2016, foi escolhido para esta investigação por apresentar um momento histórico importante e que influenciou fortemente o desenvolvimento da Ciência na época. Esse filme foi baseado na história real de três mulheres negras (Katherine Johnson, Dorothy Vaughn e Mary Jackson) que trabalharam na NASA (Agência Espacial Americana) na década de 1960, em plena Guerra Fria. Nesse período, no qual Estudos Unidos e União Soviética disputaram a soberania na corrida espacial, essas mulheres lidaram com a segregação racial e de gênero, tendo ficado reconhecidas por suas contribuições à ciência. Esse contexto nos deu indicativos sobre aspectos da $\mathrm{NdC}$ que poderiam ser discutidos. A Recebido em: 17/05/2021 
metodologia para a pesquisa foi dividida em duas partes: a primeira correspondeu à seleção dos aspectos consensuais identificados no filme; a segunda parte correspondeu à análise fílmica, na qual foi possível identificar aspectos considerados relevantes e potenciais para discussões que podem ser mediadas em sala de aula. Esta pesquisa é de abordagem qualitativa, e o tratamento dos dados foi realizado a partir da técnica de análise fílmica.

\section{1 - SELEÇÃO DOS ASPECTOS CONSENSUAIS}

Para selecionar os aspectos consensuais a serem analisados, o filme foi assistido na íntegra para obtenção de noção inicial dos consensos que possivelmente poderiam estar presentes nas cenas. O Quadro 1 destaca os aspectos consensuais que foram previamente identificados e selecionados para posterior análise fílmica. $\mathrm{Na}$ análise, verificou-se a relação entre o contexto das cenas e os aspectos consensuais presentes na literatura, identificando, dessa forma, se as cenas possuem potencial para mediar discussões sobre a NdC.

Quadro 1: Descrição dos aspectos consensuais analisados no filme

\begin{tabular}{|c|c|c|}
\hline Aspectos consensuais & dos aspectos & $\begin{array}{l}\text { Contextos a serem } \\
\text { analisados no filme }\end{array}$ \\
\hline \multirow{2}{*}{$\begin{array}{l}\text { 1.A Ciência é influenciada pelo } \\
\text { contexto social, cultural, político } \\
\text { etc., no qual ela é construída e; } \\
\text { 2.A Ciência é mutável, dinâmica e } \\
\text { tem como objetivo buscar explicar } \\
\text { os fenômenos naturais. }\end{array}$} & \multirow{2}{*}{$\begin{array}{l}\text { Nesse aspecto evidencia-se que a } \\
\text { Ciência não é neutra e o cientista se } \\
\text { deixa influenciar por suas crenças e } \\
\text { valores, adquiridas no contexto em } \\
\text { que vive. }\end{array}$} & $\begin{array}{l}\text { A mulher como } \\
\text { cientista. }\end{array}$ \\
\hline & & $\begin{array}{lr}\text { Influência da } & \text { Corrida } \\
\text { espacial } & \text { no } \\
\text { desenvolvimento } & \text { da } \\
\text { Ciência. } & \end{array}$ \\
\hline $\begin{array}{l}\text { 3. Ciência, tecnologia e sociedade são } \\
\text { correlacionadas. }\end{array}$ & $\begin{array}{llr}\text { Da mesma forma que o contexto } \\
\text { histórico } \\
\text { desenvolvimento da ciência, os } \\
\text { avanços da ciência influenciam a } \\
\text { configuração da sociedade e da } \\
\text { cultura na qual ela está integrada. }\end{array}$ & $\begin{array}{lr}\text { Como o } & \text { conhecimento } \\
\text { produzido } & \text { durante a } \\
\text { Corrida } & \text { Espacial } \\
\text { influencia a } & \text { sociedade } \\
\text { naquela época. } & \end{array}$ \\
\hline $\begin{array}{l}\text { 4.Não existe um único método } \\
\text { científico }\end{array}$ & $\begin{array}{l}\text { Há uma ideia de que existe um } \\
\text { procedimento passo-a- passo que os } \\
\text { cientistas usam para fazer ciência, } \\
\text { entretanto ainda que na maior parte } \\
\text { das vezes os cientistas sigam um } \\
\text { método, os pesquisadores } \\
\text { concordam que não há uma única } \\
\text { forma ou método de fazer Ciência. }\end{array}$ & $\begin{array}{l}\text { Como a ciência conta } \\
\text { com o trabalho em } \\
\text { equipe ou de diversas } \\
\text { equipes para seu } \\
\text { desenvolvimento, além } \\
\text { de não ocorrer apenas em } \\
\text { laboratórios. }\end{array}$ \\
\hline
\end{tabular}

Fonte: Autoria própria

Recebido em: 17/05/2021

Aceite em: $31 / 08 / 2021$ 
É importante ressaltar que outros aspectos poderiam ser identificados, pois tal identificação pode ocorrer a partir de diferentes olhares. A análise fílmica, que será apresentada a seguir, auxiliou na percepção dos aspectos selecionados.

\subsection{ANÁLISE FÍLMICA}

O método de análise fílmica, segundo Vanoye e Galiote-lété (1994), consiste em desmontar o filme e reconstruí-lo de acordo com um ou vários objetivos. Nesse sentido, antes de iniciar a análise de um filme, é necessário ter em mente qual o contexto/objetivo em que se deseja utilizá-lo, pois assim pode-se enquadrar a análise pretendida. Segundo Penafria (2009), existem 3 tipos de análise fílmica: a) análise textual; b) análise de conteúdo; c) análise da imagem e som. A análise de conteúdo considera o filme como um relato, e analisa apenas o tema que o filme traz (PENAFRIA, 2009). Como o objetivo foi analisar a presença de conteúdo sobre aspectos consensuais da $\mathrm{NdC}$, a técnica utilizada na pesquisa foi a análise de conteúdo.

Desmontar o filme é a primeira etapa da análise e consiste em separar, extrair, destacar e denominar matérias e elementos que se deseja analisar. A próxima etapa consiste em estabelecer conexões entre os elementos isolados, compreendendo como eles se relacionam para construir o filme no seu todo. É importante evidenciar que o analista traz algo novo para o filme, devido à subjetividade empregada durante a atividade de análise e os objetivos pelos quais o filme está sendo analisado (VANOYE;

GALIOT-LÉTÉ, 1994). Os mesmos autores também apontam que:

Os limites dessa invenção, dessa "criação" são, contudo, muito estritos. O analista deve de fato respeitar um princípio fundamental de legitimação: partindo dos elementos da descrição lançados para fora do filme, devemos voltar ao filme quando da reconstrução, a fim de evitar reconstruir um outro filme. Em outras palavras, não se deveria sucumbir à tentação de superar o filme. Os limites da "criatividade analítica" são os do próprio objeto da análise. O filme é, portanto, o ponto de partida e o ponto de chegada da análise (VANOYE; GALIOT-LÉTÉ, 1994, p.14).

Portanto, o objetivo do analista não deve ser propor algo além do que realmente o filme evidencia, e sim trazer suas interpretações dos conteúdos. As categorias foram elaboradas previamente à análise do filme, a partir do levantamento dos aspectos que são consensuais apontados na literatura (LEDERMAN, 2002; MOURA, 2014) e que serviram como diretrizes para essa elaboração. Este tipo de análise, que consiste na 
definição prévia das categorias analíticas em que os resultados serão agrupados, é descrita por Laville e Dionne (2008, p.220) como um "modelo fechado" no qual "... o pesquisador decide a priori categorias, apoiando-se em um ponto de vista teórico que se propõe o mais frequentemente submeter a prova da realidade".

A análise fílmica necessitou, portanto, de um processo de revisão cauteloso, procedimento importante para evitar que ocorressem interpretações incoerentes. Sendo assim, a análise do filme foi desenvolvida durante três meses. Nesse período cada cena ou trecho que possuíssem possíveis aspectos da $\mathrm{NdC}$ foram analisados e avaliados. Após essa análise, os dados foram organizados em um quadro, que será apresentado no item Resultados e Discussão.

\section{RESULTADOS E DISCUSSÃO DA ANÁLISE FÍLMICA DO CONTEÚDO}

Após assistir ao filme diversas vezes e avaliar as possibilidades, nove cenas foram selecionadas. O Quadro 2 apresenta as cenas que, no entendimento das autoras, revelaram ser potenciais para contribuir na mediação de discussões acerca de alguns aspectos consensuais (ACs) da $\mathrm{NdC}$ tratados na literatura.

Quadro 2: Relação entre consensos da NdC e as cenas selecionadas

\begin{tabular}{|c|c|c|c|c|}
\hline \multicolumn{5}{|c|}{ CENAS OUE SE REVELAM ASPECTOS CONSENSUAIS DA NDC } \\
\hline $\begin{array}{l}\text { TÍTULO: ESTRELAS } \\
\text { ALÉM DO TEMPO }\end{array}$ & \begin{tabular}{l|r} 
ESTRELAS & ORIGINAL: \\
MPO & HIDDEN FIGURES
\end{tabular} & \multicolumn{2}{|c|}{$\begin{array}{l}\text { GÊNERO: } \\
\text { BIOGRAFIA }\end{array}$} & DRAMA; \\
\hline \multicolumn{5}{|c|}{ CENAS } \\
\hline $\begin{array}{c}\text { Aspecto } \\
\text { Consensual }\end{array}$ & \multicolumn{2}{|c|}{$\begin{array}{l}\text { DESCRIÇÃO DA CENAS RELACIONADAS } \\
\text { COM OS CONSENSOS }\end{array}$} & INÍCIO & FINAL \\
\hline \multirow{6}{*}{$\begin{array}{l}\text { 1.A Ciência é } \\
\text { influenciada } \\
\text { pelo contexto } \\
\text { social, } \\
\text { cultural, } \\
\text { político etc., } \\
\text { no qual ela é } \\
\text { construída e; }\end{array}$} & \multicolumn{2}{|c|}{$\begin{array}{l}\text { I. Policial não acredita que Katherine, Dorothy Vaughn e Mary } \\
\text { Jackson são contratadas para trabalhar na NASA. }\end{array}$} & 00:04:30 & 00:05:59 \\
\hline & \multicolumn{2}{|c|}{$\begin{array}{l}\text { II. Ocorre um diálogo entre um engenheiro judeu e Mary, no } \\
\text { qual ele evidencia que há sim possibilidades para que ela seja } \\
\text { também uma engenheira, ironizando o fato de ele ser um } \\
\text { engenheiro judeu. }\end{array}$} & 00:13:05 & $00: 15: 47$ \\
\hline & \multicolumn{2}{|c|}{$\begin{array}{l}\text { III. Ketherinne conhece o coronel Johnson, e durante o diálogo } \\
\text { que ocorre nesse momento ele evidencia em sua fala } \\
\text { preconceitos, por duvidar que uma mulher negra faça trabalhos } \\
\text { considerados difíceis intelectualmente. }\end{array}$} & $00: 36: 11$ & $00: 37: 36$ \\
\hline & \multicolumn{2}{|c|}{$\begin{array}{l}\text { IV. Mary precisa estudar em uma escola de brancos para } \\
\text { conquistar seu desejo de ser engenheira da NASA. Para isso, } \\
\text { ela passa por uma audição na qual argumenta com um juiz para } \\
\text { conseguir a vaga. }\end{array}$} & $01: 10: 36$ & $01: 13: 24$ \\
\hline & \multicolumn{2}{|c|}{$\begin{array}{l}\text { V. No primeiro dia de aula só há homens brancos na sala, que } \\
\text { ficam espantados com a presença de Mary. Ao se apresentar } \\
\text { para o professor, este evidencia que o currículo do curso não foi } \\
\text { feito para ensinar uma mulher. }\end{array}$} & $01: 30: 57$ & $01: 31: 42$ \\
\hline & \multicolumn{2}{|c|}{$\begin{array}{l}\text { VI. O retorno de uma cadela russa para a Terra após ter sido } \\
\text { mandada ao espaço deixa o Sr. Webb nervoso e exigente frente }\end{array}$} & 00:08:12 & 00:09:12 \\
\hline
\end{tabular}

Recebido em: $17 / 05 / 2021$

Aceite em: $31 / 08 / 2021$ 


\begin{tabular}{|c|c|c|c|}
\hline \multirow{2}{*}{$\begin{array}{l}\text { fenômenos } \\
\text { naturais. }\end{array}$} & à ameaça da Rússia na Corrida Espacial. & & \\
\hline & $\begin{array}{l}\text { VII. O chefe Al Harrison, em uma reunião após a perda da } \\
\text { capsula de lançamento durante um teste, evidencia em sua fala } \\
\text { a urgência de que o governo invista mais recursos para as } \\
\text { pesquisas sobre as viagens espaciais. }\end{array}$ & $01: 15: 44$ & 01:16:33 \\
\hline $\begin{array}{lr}\text { 3. Ciência, } \\
\text { tecnologia } & \text { e } \\
\text { sociedade } & \text { são } \\
\text { correlacionada } \\
\text { s. }\end{array}$ & $\begin{array}{l}\text { VIII. Após Glenn pousar em segurança, várias pessoas } \\
\text { comemoram essa grande conquista, inclusive os participantes } \\
\text { do projeto. Al Harrison conversa com Katherine e evidencia as } \\
\text { novas possibilidades que um conhecimento produzido pode } \\
\text { despertar para o futuro. }\end{array}$ & $01: 56: 25$ & 01:57:03 \\
\hline $\begin{array}{l}\text { 4.Não existe } \\
\text { um } \\
\text { método único } \\
\text { científico. }\end{array}$ & $\begin{array}{l}\text { IX. Katherine discute com os outros pesquisadores e o chefe } \\
\text { sobre as limitações dos cálculos que estão sendo utilizados, } \\
\text { propondo outras possibilidades. O chefe acaba fazendo uma } \\
\text { reflexão que possibilita a resolução dessas limitações. }\end{array}$ & $01: 31: 42$ & $01: 33: 28$ \\
\hline
\end{tabular}

Fonte: Autoria própria

A organização da análise das cenas descritas no Quadro 2 ocorreu da seguinte forma: as cenas foram analisadas de acordo com os consensos da $\mathrm{NdC}$ que apresentam; as possíveis relações entre as cenas e os aspectos consensuais presentes na literatura foram identificadas; e, ao longo da discussão, as cenas mais específicas sobre determinado aspecto indicado no Quadro 2 foram destacadas. Tais indicações podem contribuir para a discussão de algum aspecto consensual mais específico da NdC.

3.1 Análise das cenas selecionadas e suas relações com os Aspectos consensuais

\subsection{1 - Aspectos consensuais 1 e 2 (Quadro 2)}

Os aspectos consensuais 1 e 2 se relacionam fortemente. $\mathrm{O}$ aspecto 1 aborda $\mathrm{O}$ caráter dependente entre o que está em estudo nas pesquisas científicas e o contexto social no qual esses estudos estão inseridos. Por exemplo: a pandemia de COVID -19 despertou interesse de muitos governos no desenvolvimento de vacinas. Nesse sentido, houve muito investimento para atingir esse fim, ou seja, o contexto pandêmico afetou o rumo para o qual os cientistas voltaram sua atenção. Já o aspecto 2 aborda o carácter dinâmico da Ciência, que é consequência da sua dependência com o contexto histórico, filosófico e sociológico. Nas cenas I a IV, o contexto machista e racista que pairava sobre os EUA nos anos 1960 se faz presente. Nessa época, o movimento supremacista branco era muito forte e a década foi marcada por protestos pela garantia de direitos civis dos negros e negras americanas (DAVIS, 2016). As políticas de segregação dificultavam a inserção, o reconhecimento e os estudos desenvolvidos pelos negros, mas principalmente pelas mulheres negras na Ciência. Esse fato fica evidente, por exemplo, no momento em que as cientistas são ironizadas por afirmarem que trabalham na NASA

Recebido em: $17 / 05 / 2021$

Aceite em: $31 / 08 / 2021$ 
(cena I) e na luta necessária para que Mary consiga seu diploma de engenheira (cena IV), sendo obrigada a frequentar uma sala apenas com homens brancos (cena V). Já nas cenas VI e VII, é possível notar como a Guerra Fria gerou um clima de competição entre os Estados Unidos e a União das República Socialistas Soviéticas (URSS) para mandar o primeiro homem para o espaço (cena VI), implicando em grandes investimentos no desenvolvimento de pesquisas científicas nessa área (cena VII), em especial na NASA.

Portanto, as cenas I, II, III, IV, V, VI e VII revelam como o trabalho das cientistas foi influenciado pelo contexto histórico, social, político e cultural da época. Diversos autores tratam sobre como a Ciência é dinâmica e influenciada pelo seu contexto histórico (MOURA, 2014, LEDERMAN, 2002, MATTHEWS, 2005, PÉREZ, 2001). Lederman (2002) destaca que a Ciência é um empreendimento humano que afeta e é afetada pela cultura predominante na qual for desenvolvida. Alguns elementos aos quais o autor refere-se como influenciadores incluem "a estrutura social, política, de poder, os fatores socioeconômicos, filosofia e religião" (LEDERMAN, 2002, p.501, tradução nossa). Nesse sentido, observou-se a possibilidade de discutir a não neutralidade da Ciência, pois a segregação racial, a luta por direitos civis dos negros e negras, bem como a Corrida Espacial, foram fortes fatores de influência na aceitação, rejeição e na forma como se desenvolveram as ideias científicas (MOURA, 2014). Nota-se como a produção do conhecimento científico é mutável e influenciada pelas ideologias de classe, raça, gênero e religião, corroborando para a não neutralidade da Ciência.

Além da segregação racial, também pode-se discutir sobre a tendência da Ciência ser geralmente construída por homens (BLEIER, 1984; HARDING, 1986 apud MATTHEWS, 1995), essa característica é proveniente de discriminações de origem social e de gênero (PEREZ et al, 2001). Nas cenas elencadas, assim como em boa parte do filme, fica clara a influência desses preconceitos, ideologias e culturas sobre a Ciência naquela época. Também fica evidente como as decisões a serem tomadas pelos(as) cientistas podem ser afetadas por suas relações sociais, religiosas e valores éticos individuais, isso devido à condição humana, na qual eles se encontram (ALONSO, MAS, DÍAZ, ROMERO, 2007). A Corrida Espacial influenciou fortemente os trabalhos dos cientistas norte-americanos da época, que sofriam grande pressão e 
contavam com investimentos para conseguirem chegar ao espaço antes da URSS. Assim, é possível perceber que o conhecimento científico, incluindo fatos, teorias e leis, está sujeito a modificações e adaptações. Essas alterações ocorrem na "medida em que as evidencias existentes são reinterpretadas à luz de novos avanços teóricos, mudanças nos interesses sociais e políticos, nas esferas culturais ou com mudanças nas instruções dos programas de pesquisa'” (LEDERMAN, p.503, 2002, tradução nossa).

\subsubsection{Aspecto consensual 3 (Quadro 2)}

$\mathrm{O}$ aspecto consensual 3 refere-se à relação existente entre o desenvolvimento que ocorre na Ciência sobre os avanços tecnológicos e mudanças sociais. Esses fatores se correlacionam de modo que alterações em um setor influenciam os outros dois. $\mathrm{Na}$ cena VIII nota-se as expectativas sobre as novas possibilidades que o desenvolvimento científico proporciona para a sociedade na qual se insere, expondo as relações coexistentes entre ciência, tecnologia e sociedade (DE ARAÚJO SILVA; ROBAINA, 2020). Isso ocorre porque a população americana da época estava ansiosa para vencer a Corrida Especial. Nesse sentido, toda a mídia televisiva estava transmitindo o momento no qual poderia ser comemorado tal feito. Assim, nota-se que a população comemora as novas possibilidades que surgem com o desenvolvimento científico-tecnológico e a comunidade científica também, como é possível verificar no diálogo entre Al Harrison e Katherine, no qual eles começam a pensar na possibilidade de chegar à Lua (cena VIII).

Segundo Pérez et al (2001), assim como o momento histórico possui grande influência sobre os caminhos pelos quais a Ciência se direcionará, as ações científicas possuem impactos sobre o meio físico e social em que se desenvolvem, podendo tanto contribuir para a melhoria da vida humana quanto desencadear graves problemas (PRAIA et al, 2007; DE ARAÚJO SILVA; ROBAINA, 2020). Dessa forma, podemos afirmar que as Ciências e as tecnologias auxiliaram significativamente para organização das sociedades atuais, partindo do desenvolvimento de grandes formas de “comunicação, transporte, energia, alimentação, sanidade e bem-estar social até os detalhes da vida doméstica e pessoal, tanto nos aspectos mais positivos quanto nos mais polêmicos e negativos"' (ALONSO et al, 2007, p.39). 


\subsection{3 - Aspecto consensual 4 (Quadro 2):}

Visualiza-se, ainda hoje, que o conhecimento científico é desenvolvido seguindo uma "receita de bolo" muito bem definida e única, que não sofre alterações durante o percurso das pesquisas. O aspecto consensual 4, portanto, busca tratar questões que revelam que a Ciência não se desenvolve de forma linear, produzida por cientistas geniais e isolados, mas sim por diferentes equipes que não devem apresentar limitações quanto aos seus e suas integrantes em aspectos relacionados a gênero ou raça. Nesse sentido, a partir da cena IX é possível observar sobre como a ciência se desenvolve em equipe, diferente das concepções de pessoas que afirmam que o desenvolvimento da ciência ocorre sempre em laboratórios e por gênios isolados (PÉREZ et al., 2001). É através do compartilhamento de dúvidas e possibilidades que se torna possível resolver grandes problemas e questões científicas, fazendo avançar a fronteira do conhecimento. Durante diversos momentos no filme nota-se a existência de diferentes equipes trabalhando para um único objetivo final, o de vencer a Corrida Espacial. Para Pérez et al. (2001) e Praia et al. (2007), a Ciência é produzida partindo do trabalho coletivo, cooperativo e do intercâmbio de saberes entre equipes, o que revela a falta de sentido em uma investigação completamente autônoma.

Segundo Lederman et al. (2002), um outro conceito equivocado presente nas ideias das pessoas é a concepção de que exista um único método científico. Essa concepção difunde a crença de que há um conjunto de ações ordenadas, predeterminadas, infalíveis e de suposta neutralidade que todos os cientistas seguem para fazer Ciência (PRAIA et al., 2007). Existe um consenso muito amplo entre os pesquisadores de que não há um conjunto de regras que os cientistas usam ou devam usar para obter sempre os resultados esperados. Tanto as metodologias quanto os resultados podem ser variados, o que possibilita espaço para desacordos e novos estudos (MOURA, 2014). Mesmo que não exista um método bem definido, é verdade que os cientistas "observam, comparam, medem, testam, especulam, hipotetizam, criam ideias e ferramentas conceituais e constroem teorias e explicações. No entanto, não há uma sequência única que os conduzam sem cessar a soluções e respostas válidas ou funcionais" (LEDERMAN et al, 2002, p.501, tradução nossa). É importante haver método para construção de conhecimento científico, mas existem várias formas para essa construção.

Recebido em: $17 / 05 / 2021$

Aceite em: $31 / 08 / 2021$ 


\section{CONSIDERAÇÕES FINAIS}

O objetivo desta pesquisa consistiu em analisar as possibilidades didáticas do filme "Estrelas além do tempo" para discutir alguns aspectos da $\mathrm{NdC}$ em espaços educacionais. Os resultados discutidos durante o trabalho, a partir das investigações realizadas, sugerem que o filme apresenta cenas potenciais para mediar discussões acerca de aspectos consensuais da $\mathrm{NdC}$. Isso se deve à presença de cenas que mostram alguns dos aspectos consensuais que foram escolhidos para a análise, como, por exemplo, a influência do contexto histórico-social, político etc., sobre o desenvolvimento da Ciência. Além disso, o uso de filmes como recurso didático pode auxiliar na promoção do interesse pelo conteúdo devido a sua capacidade de entreter, emocionar etc.

Esta pesquisa, portanto, procurou contribuir para o ensino de Ciências ao evidenciar possibilidades da utilização do filme escolhido com a intenção de promover discussões de aspectos consensuais sobre a $\mathrm{NdC}$ no ensino básico e superior, ou ainda em espaços não formais de educação. Outra possibilidade é a utilização desse recurso na formação inicial e continuada de professores(as) de Ciências Naturais, que podem incluir essa temática tão relevante em suas aulas, propiciando a (re)significação de possíveis concepções reducionistas ou equivocadas sobre os (as) cientistas e a Ciência que os(as) estudantes possam apresentar.

Como sugestões e possibilidades para a utilização do filme analisado, as discussões, em qualquer nível de ensino (básico e superior), podem ser realizadas como em um cine-debate, no qual, após a exibição do filme, os participantes possam dialogar sobre suas impressões e, a partir da mediação dos professores, por exemplo, fazer discussões sobre os aspectos consensuais da NdC. Também é possível discutir as cenas separadamente, de acordo com o tema que se deseja tratar, utilizando, por exemplo, as cenas que evidenciam a discriminação racial ou as dificuldades enfrentadas pelas mulheres, principalmente as negras, em sua inserção no meio científico. Outra possibilidade é a construção de narrativas pelos estudantes, nas quais terão a oportunidade de fazer reflexões sobre o contexto do filme ou das cenas. 
$\mathrm{Na}$ formação de professores, além da proposta de cine-debate, é também possível a abordagem da NdC por meio de uma sequência didática, na qual o professor formador poderá planejar uma fundamentação prévia a partir de artigos científicos que discutem o tema, a reprodução do filme ou das cenas selecionadas aos professores em formação, finalizando a sequência com a produção de argumentações ou também de elaboração de novas propostas de atividades pedagógicas.

Assim, conclui-se que apesar de o filme mostrar uma realidade ocorrida há 60 anos, as temáticas nele abordadas ainda se fazem muito presentes atualmente e, portanto, são relevantes para serem incluídas nas salas de aulas, favorecendo a desconstrução de preconceitos raciais e de gênero, como também concepções equivocadas sobre o trabalho científico.

Nota: Katherine Johnson faleceu no dia 24 de fevereiro de 2020, aos 101 anos. Em 2015, ela recebeu do presidente Barack Obama a Medalha Presidencial da Liberdade, importante condecoração civil americana. A NASA possui um centro de pesquisa computacional com o nome de Katherine.

\section{REFERÊNCIAS}

ALONSO, Ángel Vázquez et al. Consensos sobre la naturaleza de la ciencia: la comunidad tecnocientífica. Revista electrónica de enseñanza de las Ciencias, v. 6, n. 2, p. 331-363, 2007.

AZEVEDO, N.H.; SCARPA, D.L.S.; Revisão Sistemática de Trabalhos sobre Concepções de Natureza da Ciência no Ensino de Ciências. Revista Brasileira de Pesquisa em Educação em Ciências, v.17, n.2, p.579-619, 2017.

BARTELMEBS, Roberta Chiesa; VENTURI, Tiago; DE SOUSA, Robson Simplicio. Pandemia, negacionismo científico, pós-verdade: contribuições da Pós-graduação em Educação em Ciências na Formação de Professores. Revista Insignare Scientia-RIS, v. 4, n. 5, p. 64-85, 2021.

BRASIL. Ministério da Educação e Cultura. Base Nacional Comum Curricular. Educação Infantil e Ensino Fundamental. 2018.

Parâmetros curriculares nacionais: ensino médio. Brasília: MEC;

SEMTEC, 1999.

Ministério da Educação e Cultura. Secretaria de Educação Fundamental;

Parâmetros Curriculares Nacionais: Introdução, MEC: Brasília, 1998.

BOAS, Anderson Vilas et al. História da ciência e natureza da ciência: debates e consensos. Caderno Brasileiro de Ensino de Física, v. 30, n. 2, p. 287-322, 2013.

Recebido em: 17/05/2021

Aceite em: $31 / 08 / 2021$ 
CARRERA, Vanessa. Mendes., ARROIO, Agnaldo. Filmes comerciais no ensino de ciências: tendências no ENPEC entre 1997 e 2009, 2011. Disponível em: < http://abrapecnet.org.br/atas_enpec/viiienpec/resumos/R0725-1.pdf > Acessado em: $<22$ de abril de 2021>.

COLAGRANDE, Elaine A; ARROIO, Agnaldo. Representações sociais sobre ciência e cientista-importante discussão na formação de professores de química. Educação

Química en Punto de Vista, v. 2, n. 1, 2018. Disponível em: < https://revistas.unila.edu.br/eqpv/article/view/1012/1155> Acessado em: $<22$ de abril de 2021>.

DAVIS, Angela. Mulheres, raça e classe. São Paulo: Boitempo, 2016.

DE ARAUJO SILVA, Cristine Roman Cardoso; ROBAINA, José Vicente Lima. O estado da arte das pesquisas acadêmicas sobre CTSA no período de 2014 até 2018.

Revista Insignare Scientia-RIS, v. 3, n. 2, p. 85-100, 2020. Disponível em< https://periodicos.uffs.edu.br/index.php/RIS/article/view/11070> Acessado em: 10 de mai. 2021.

DOS SANTOS, Paloma Nascimento; DA SILVA AQUINO, Kátia Aparecida. Utilização do cinema na sala de aula: aplicação da química dos perfumes no ensino de funções orgânicas oxigenadas e bioquímica. Química Nova na Escola, v. 33, n.3, 2011. Disponível em:<

http://www.educadores.diaadia.pr.gov.br/arquivos/File/outubro2011/quimica_artigos/ci nema_sala_aula_art.pdf $>$ Acessado em: $<11$ de maio de 2021>

DOS SANTOS, Eliane Gonçalves; DE ARAÚJO, Maria Cristina Pansera. Implicações de um processo Formativo de professores mediado por filmes, na constituição de uma visão ampliada de Saúde. Revista Insignare Scientia-RIS, v. 3, n. 5, p. 517-539, 2020. Disponível em: $<$ https://periodicos.uffs.edu.br/index.php/RIS/article/view/11902> Acessado em: $<15$ de maio de 2021 $>$.

FANFA, Michele Souza et al. Espaços de Educação Não Formal e Alfabetização Científica: um olhar sob a exposição do MAVUSP. Revista Insignare Scientia-RIS, v. 3, n. 5, p. 98-113, 2020. Disponível em:< https://periodicos.uffs.edu.br/index.php/RIS/article/view/11359> Acessado em: 19 de maio de 2021.

GARCÍA-BORRÁS, Francisco José. Ágora: una aproximación al nacimiento del saber científico. Revista Eureka sobre Enseñanza y Divulgación de las Ciencias, v. 7, n. 3, p. 708-728, 2010.

HARRES, João Batista Siqueira. Uma revisão de pesquisas nas concepções de professores sobre a natureza da ciência e suas implicações para o ensino. Investigações no ensino de Química, v.4, n.3, p. 197-211, 1999. Disponível em:< https://www.if.ufrgs.br/cref/ojs/index.php/ienci/article/view/603/pdf> Acessado em:< 15 de dezembro de 2020.

Recebido em: 17/05/2021

Aceite em: 31 /08/2021 
KOSMINSKY, Luis; GIORDAN, Marcelo. Visões de ciências e sobre cientista entre estudantes do ensino médio. Química nova na escola, v. 15, n. 1, p. 11-18, 2002. Disponível em: $<$ http://www.lapeq.fe.usp.br/textos/ec/ecpdf/kosminsky_giordan-qnesc2002.pdf $>$ Acessado em: $<14$ de dezembro de 2020>.

LAVILLE, et al. A construção do saber. Belo Horizonte: UFMG,1999.

LEDERMAN, Norm G. et al. Views of nature of science questionnaire: Toward valid and meaningful assessment of learners' conceptions of nature of science. Journal of research in science teaching, v. 39, n. 6, p. 497-521, 2002.

LEDERMAN, N. G. Research on Nature of Science: Reflections on the Past, Anticipations of the Future; Asia-Pacific Forum on Science Learning and Teaching, v.7, n.1, 2006.

MATTHEWS, Michael S. História Filosofia e Ensino de Ciências: A Tendência Atual de Aproximação, Caderno Brasileiro de Ensino de Física, v.12, n.3, p.164-214, 1995. MEGLHIORATTI, Fernanda Aparecida; BORTOLOZZI, Jehud; CALDEIRA, Ana Maria de Andrade. A construção da ciência e o ensino de Ciências. Revista Eletrônica de Pedagogia. v.5, 2005. Disponível em <:

http://faef.revista.inf.br/imagens_arquivos/arquivos_destaque/QEt3ntns1ShfOJU_20136-28-12-7-40.pdf > Acessado em:<19 de março de 2021>.

MOURA, Breno Arsioli. O que é natureza da Ciência e qual sua relação com a História e Filosofia da Ciência. Revista Brasileira de História da Ciência, v. 7, n. 1, p. 32-46, 2014. Disponível em<:

https://www.sbhc.org.br/arquivo/download?ID_ARQUIVO=1932> Acessado em: 19 mar. 2021.

NAPOLITANO, Marcos. Como usar o cinema na sala de aula. 4. ed. São Paulo: Contexto, 2006.

PENAFRIA, Manuela. Análise de Filmes - conceitos e metodologia (s). In: VI Congresso Sopcom. p. 6-7, 2009.

PÉREZ, Daniel Gil et al. Para uma imagem não deformada do trabalho científico. Ciência \& Educação (Bauru), v. 7, n. 2, p. 125-153, 2001. Disponível em:< https://www.scielo.br/pdf/ciedu/v7n2/01.pdf> Acessado em: 21 abr. 2021.

POMBO, Fernanda. Mariano. Z; LAMBACH, Marcelo. As visões sobre ciência e cientistas dos estudantes de química da EJA e as relações com os processos de ensino e aprendizagem. Química Nova na Escola, São Paulo-SP, v.39, n.3, p. 237-244, 2017.

PRAIA, João; GIL-PÉREZ, Daniel; VILCHES, Amparo. O papel da natureza da ciência na educação para a cidadania. Ciência \& Educação (Bauru), v. 13, n. 2, p. 141-156, 2007. Disponível em: $<$ https://www.scielo.br/scielo.php?pid=s1516-

73132007000200001\&script=sci_abstract\&tlng=pt> Acessado em: 21 abr. 2021.

Recebido em: 17/05/2021

Aceite em: $31 / 08 / 2021$ 
ROSA, P. R. S; O Uso dos Recursos Audiovisuais e o Ensino de Ciências. Caderno Brasileiro de Ensino de Física, v.17, n.1: p.33-49, 2000.

REIS, P. et al. Concepções sobre os cientistas em alunos do $1^{\circ}$ ciclo do Ensino Básico: "Poções, máquinas, monstros, invenções e outras coisas malucas". Revista Electrónica de Enseñanza de las Ciencias, Vigo, v. 5, n.1, p.51-74, 2006.

SASSERON, Lúcia Helena. Alfabetização científica, ensino por investigação e argumentação: relações entre ciências da natureza e escola. Ensaio Pesquisa em Educação em Ciências (Belo Horizonte), v. 17, n. spe, p. 49-67, 2015. Disponível em< https://www.scielo.br/pdf/epec/v17nspe/1983-2117-epec-17-0s-00049.pdf> Acessado em: 22 mar. 2021.

SCHWARTZMAN, Simon. A ciência da ciência. Ciência Hoje, Rio de Janeiro, v.2, n. 11, p. 54-59, 1984.

MESQUITA, Nyuara Araújo da Silva; SOARES, Márlon Herbert Flora Barbosa. Visões de Ciências de Professores de Química: a mídia e as reflexões no ambiente escolar no nível médio de ensino. Química Nova, v. 31, n. 7, p. 1875-1880, 2008. Disponível em: $<$ https://www.scielo.br/scielo.php?pid=S0100-

40422008000700047\&script=sci_abstract\&tlng=es> Acessado em: 22 mar. 2021.

VÁZQUEZ, et al. Concensos sobre a Natureza da Ciência: A Ciência e a Tenologia na Sociedade. Química Nova na Escola. n.27, 2008. Disponível em<

http://qnesc.sbq.org.br/online/qnesc27/07-ibero-6.pdf> Acessado em: 22 mar. 2021.

VANOYE, Francis; GOLIOT-LÉTÉ, Anne. Ensaio sobre a análise fílmica. 5 ed. Trad. Marina Appenzeller. Campinas: Papyrus, 2008:1994. 